\title{
Performance following a night of reduced sleep
}

ROBERT T. WILKINSON, ROBERT S. EDWARDS AND ERIC HAINES

APPLIED PSYCHOLOGY RESEARCH UNIT, CAMBRIDGE, ENGLAND

Six Ss worked a full day, mainly on vigilance and calcula tion tests, for two successive days in each of six successive weeks. On the preceding nights they were allowed $0,1,2,3$, 5 , or $7 \frac{1}{2} \mathrm{hr}$. sleep varying according to the week of testing. Less than $5 \mathrm{hr}$. sleep on a single night impaired vigilance; less than $3 \mathrm{hr}$. impaired calculation.

Although there have been many studies of the effect upon performance of one or more days of complete sleep deprivation, there appear to be no satisfactory data upon the effect of a single night of reduced sleep. There are two main reasons for this: either the scale of the experiment precluded the use of sufficient Ss (Smith, 1916; Husband, 1935) or insensitive performance tasks were used (Webb \& Agnew, 1965). The present study has sought to remedy these defects.

Method

Six enlisted men carried out performance tests from 8 A.M. to 10:30 P.M. (with relatively short breaks for meals) on the Wednesday and Thursday of six successive weeks. On each of the nights preceding the days of testing they slept either $0,1,2,3,5$, or $7-1 / 2 \mathrm{hr}$. according to the week of testing. Thus by the end of the sixth week each $\mathrm{S}$ had met each of these conditions of sleep, the order of their presentation being randomized among Ss with the constraint that on any given night each of the Ss received different amounts of sleep. Where sleep was taken Ss were always wakened at 6:30 A.M., the partial sleep deprivation being achieved by delaying their retirement to bed. They were under constant supervision, except when they were sleeping, from the morning of Tuesday until the end of their second testing day on Thursday. When not carrying out the

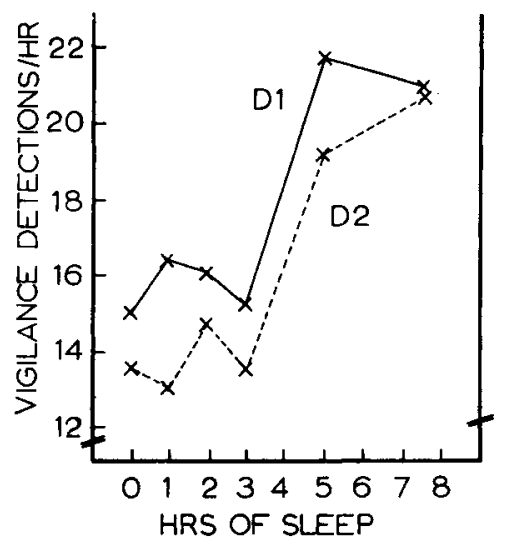

Fig. 1. The effect of $0,1,2,3,5$, or $7 \frac{1 / 2}{h r}$. sleep on two successive nights upon performance the following days (D1 and D2). The score is that of signals detected in the vigilance task. performance tests they were employed either in routine duties or in light leisure activities. The performance days were occupied mainly in carrying out two tests, one vigilance and one of routine addition, each lasting $1 \mathrm{hr}$. and, in general, alternating throughout the day. In the vigilance test the Ss heard 1/2-sec.tones coming at 2-sec. intervals. Occasionally one of these tones was slightly shorter than the rest; the S's task was to detect and report these "signals." The signals occurred at a rate of $40 / \mathrm{hr}$. and were irregularly spaced in a way which appeared random to the S. A number of different signal programs were used so that the occurrence of signals remained unpredictable to the Ss throughout the six weeks of testing. The S's score was the number of signals detected/1-hr. session. In the addition test the Ss were given columns of five two-digit numbers to add, again with negligible replication during the six weeks. The scores in this test were the number of sums completed and the number incorrectly added.

\section{Results}

Figure 1 (vigilance) and Fig. 2 (addition) show the average scores for each of the conditions of sleep on the first day (D1) and on the second day (D2). The significance of the differences in performance due to (1) hours of sleep, (2) the first and second days of treatment, and (3) the interaction between these two influences was examined by univariate analysis of variance. As the means under consideration were correlated, the Geisser-Greenhouse (1958) conservative test was applied.

The general trend of lowered efficiency of performance with reduced sleep was significant in two scores: detections in the vigilance task $(F=51.2, \mathrm{df}=2 / 10$,

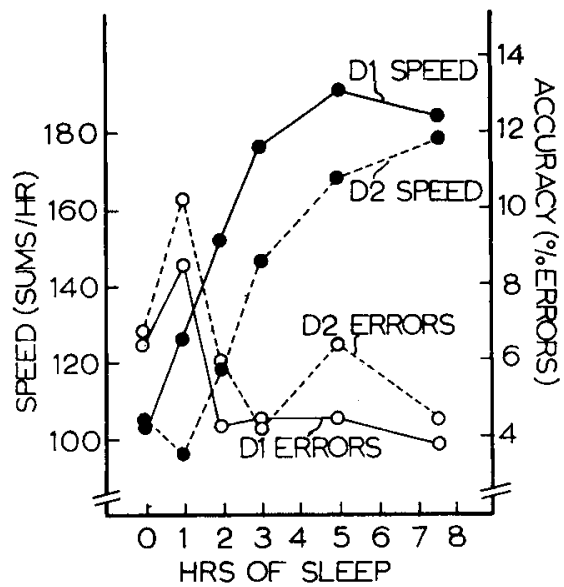

Fig. 2. As for Fig. 1 but with scores of speed (sums done/hr.) and accuracy (percent ernors) in the addition task. 
$\mathrm{p}<.01)$, and sums done $(\mathrm{F}=50.1, \mathrm{df}=2 / 10, \mathrm{p}<.01)$ in the addition task. Performance was worse on D2 than D1 again in vigilance detections and in sums done (in each case $F>7.0, \mathrm{df}=1 / 5, \mathrm{p}<.05$ ). This was presumably due to the greater sleep deprivation on D2, but the more precise indicator of the cumulative effect of reduced sleep over the two days, namely the interaction of hours of sleep with days, was not significant. In errors there were no significant differences in any of these trends.

Figures 1 and 2 show also that, although performance declined with reduced sleep, the pattern of this decline was different for different tasks. In the vigilance test (signals detected) there was little change in performance as hours were reduced from $7-1 / 2$ to 5 , a steep decline from 5 to $3 \mathrm{hr}$. ( $p<.05$, using the Wilcoxon Test (Siegel, 1956)), and little change thereafter down to $0 \mathrm{hr}$. The speed score of the adding task (sums done), however, showed quite a different picture. As the hours of sleep were reduced below 3 there was a decline in performance which, if anything, was greatest on the transition from 2 to $1 \mathrm{hr}$. Thus on D1 the combined performance with 2 and $3 \mathrm{hr}$. sleep was not significantly worse than that at 5 and $7-1 / 2 \mathrm{hr}$. combined, but considerably better than that at 0 and $1 \mathrm{hr}$. combined ( $p<.05$, Wilcoxon Test). Similar patterns appeared in errors, but they were insignificant. The significance levels given above apply to $\mathrm{D} 1$, but similar trends were apparent on $\mathrm{D} 2$ also. Discussion

The main finding of this experiment is that, if the duration of performance testing is extended so that it approximates to a normal day's work, the reduction of sleep by about half on a single night can produce a significant fall in working efficiency. The reason why previous experiments (Smith, 1916; Husband, 1935; Webb \& Agnew, 1965) have failed to show this effect of partial sleep deprivation is almost certainly that the performance tests were too short. The complete loss of one night's sleep has no effect upon the first $5 \mathrm{~min}$. of work on serial reaction tests, vigilance and adding, but a clear impairment of performance emerges when these tests are prolonged for 15 to $40 \mathrm{~min}$. (Wilkinson, 1961; 1965). The extrapolation from this that tests covering the full day (with reasonable breaks) would prove still more sensitive has been confirmed by the present study.

So far it has proved impossible to find any quantifiable impairment of performance due to selective deprivation of sleep, for example deprivation of the rapid eye movement (REM) phase of sleep (Dement, 1960) and of Stage 4 of slow wave sleep (Webb, unpublished data). As the present prolonged performance tests have proved so sensitive to partial sleep deprivation they might well reveal performance changes due to REM and Stage 4 deprivation also. Most of the REM sleep is thought to occur after the first $3 \mathrm{hr}$. of a night's sleep (Williams et al, 1964). It may be significant that it was only after the first $3 \mathrm{hr}$. that performance began to improve from the $0 \mathrm{hr}$. level of sleep in scores of detections in vigilance. This might imply that REM sleep is the more important for this task. In speed scores of adding, on the other hand, the greatest improvement in performance occurred on the transition from 0-1-2 hr. sleep, which in turn may emphasize the importance of slow wave sleep for this kind of performance. These, however, are tentative suggestions which further research must substantiate or deny.

\section{References}

Dement, W. C. The effect of dream deprivation. Science, 1960, 131 1705-1707.

Giesser, S., \& Greenhouse, S. W. An extension of Box's results on the use of the $F$ distribution in multivariate analysis. Ann. Math. Statis., 1958, 29, 885-891.

Husband, R. W. The comparative value of continuous versus interrupted sleep. J. exp. Psychol., 1935, 18, 792-796.

Siegel, S. Nonparametric statistics. New York: McGraw-Hill, 1956. Smith, M. A. A contribution to the study of fatigue. Brit. J. Psychol., 1916, 8, 327-350.

Webb, W. B., \& Agnew, H. W. Sleep: effects of a restricted regime. Science, $1965,150,1745-1746$.

Wilkinson, $\mathbf{R}$. T. Interaction of lack of sleep with knowledge of results, repeated testing, and individual differences. $J$. exp. Psychol., 1961, 62, 263-271.

Wilkinson, R. T. Sleep deprivation. In: O. G. Edholm \& A. L. Bacharach (Eds.), The physiology of human survival. New York, Academic Press, 1965.

Williams, R. L., Agnew, H. W., \& Webb, W. B. Sleep patterns in young adults: an EEG study. EEG clin. Neurophysiol., 1964, 17, 376 . 